\title{
Residual da mistura formulada dos herbicidas imazethapyr e imazapic em solo de várzea sobre azevém (Lolium multiflorum Lam.) cultivado em sucessão ao arroz tolerante
}

\author{
Carryover of the formulated mixture of the herbicides imazethapyr and imazapic \\ in lowland soils, affecting ryegrass (Lolium multiflorum Lam.) \\ Mara Grohs ${ }^{\mathrm{I}}$ Fernando Machado dos Santos ${ }^{\mathrm{II}}$ Enio Marchezan ${ }^{\mathrm{III}}$ \\ Paulo Fabrício Sachet Massoni ${ }^{\mathrm{I}}$ Diego Rost Arosemena ${ }^{\mathrm{I}}$ \\ Luis Antônio de Avila ${ }^{\text {III }}$
}

\section{- NOTA -}

\section{RESUMO}

Herbicidas do grupo das imidazolinonas, como imazethapyr e imazapic, podem persistir no solo e afetar culturas não-tolerantes cultivadas em sucessão. O objetivo do trabalho foi avaliar o efeito residual da mistura formulada de imazethapyr+imazapic sobre azevém semeado e conduzido sob condições de casa de vegetação. Para isso, inicialmente foi conduzido um experimento em campo, em que aplicou-se sobre a cultivar tolerante de arroz ("IRGA 422 CL") diferentes doses da mistura formulada de imazethapyr+imazapic,

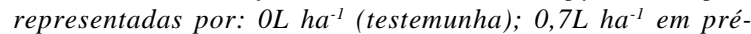

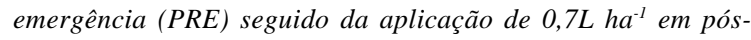
emergência (POS); 1,0L ha-1 em PRE; e 1,0L ha-1 em POS. Posteriormente, aos 194 dias após a aplicação das doses, foram coletadas amostras intactas de solo na camada de 0 $10 \mathrm{~cm}$, as quais foram utilizadas na condução de um bioensaio com azevém. Foram avaliadas a porcentagem de plantas emergidas aos três e 22 DAE (dias após a emergência) e a matéria seca do azevém aos 40 DAE. Verificou-se que a aplicação dos herbicidas na cultura do arroz no verão não ocasiona danos ao azevém semeado 194 dias após a aplicação do produto.

Palavras-chave: bioensaio, atividade residual, imidazolinonas, arroz vermelho.

\section{ABSTRACT}

Imidazolinone herbicides, such as imazethapyr and imazapic, may persist in the soil and carryover to non-tolerant crops. This work aimed at evaluating the field carryover of the formulated mixture of imazethapyr+imazapic affecting ryegrass. For this reason, a field experiment was carried out, in which

\begin{abstract}
different rates of the formulated mixture of imazethapyr and imazapic were applied on a tolerant rice cultivar ('IRGA 422 CL'): OL ha' (check plot); 0.7L ha ${ }^{-1}$ preemergence (PRE)

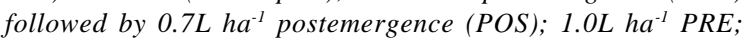

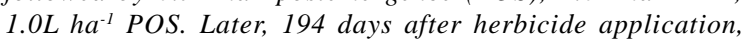
intact soils cores samples were collected at 0 to $10 \mathrm{~cm}$ depth to carry out a bioassay in greenhouse, sowing ryegrass. It was evaluated the percentage of plants established at three and 22 $D A E$ (days after emergence) and ryegrass dry biomass at 40 $D A E$. The results showed that herbicides applied on rice crop during summer does not cause damage to the ryegrass sowed 194 days after herbicide application.
\end{abstract}

Key words: bioassay, carryover, imidazolinones, red rice.

O arroz vermelho é um dos fatores mais restritivos à elevação da produtividade da lavoura orizícola no Rio Grande do Sul. A dificuldade de controle químico dessa planta daninha deve-se a semelhanças fisiológicas e bioquímicas entre o arroz vermelho e o arroz cultivado. O Sistema Clearfield ${ }^{\circledR}$ possibilita o controle químico do arroz vermelho em lavouras de arroz cultivado, por meio do uso de herbicidas do grupo químico das imidazolinonas em cultivares de arroz tolerantes (CROUGHAN, 1994).

Uma das principais características dos herbicidas desse grupo é a prolongada atividade residual no solo (LOUX et al., 1989; LOUX \& REESE, 1993), que pode variar de 31 a 410 dias para imazapic

\footnotetext{
ICurso de Agronomia, Universidade Federal de Santa Maria (UFSM), Santa Maria, RS, Brasil.

"Programa de Pós-graduação do Curso de Agronomia, UFSM, Santa Maria, RS, Brasil.

IIDepartamento de Fitotecnia, UFSM, 97105-900, Santa Maria, RS, Brasil. E-mail: emarchezan@terra.com.br. *Autor para correspondência.
} 
(GRYMES, 1995), de 60 a 360 dias para imazethapyr (GOETZ, 1990; MANGELS, 1991) e de até 436 dias para imazapyr (COX, 1996). Sua permanência no solo depende substancialmente de fatores como $\mathrm{pH}$, matéria orgânica, textura, umidade do solo (LOUX \& REESE, 1993), mineralogia, retenção de água pelo solo (GOETZ et al., 1986) e atividade dos microorganismos do solo (WITT \& FLINT, 1997). Assim, a presença de resíduos desses herbicidas pode afetar o desenvolvimento de culturas não-tolerantes semeadas em sucessão ou rotação ao arroz irrigado, como, por exemplo, o azevém (Lolium multiflorum Lam.), cultura implantada em áreas de várzeas do Rio Grande do Sul logo após a colheita do arroz.

Em vista do apresentado, o objetivo do presente trabalho foi determinar, por meio de bioensaio, a atividade residual da mistura formulada contendo os herbicidas imazethapyr (75g L $\left.\mathrm{L}^{-1}\right)$ e imazapic $\left(25 \mathrm{~g} \mathrm{~L}^{-1}\right)$ nas plantas de azevém semeado 194 dias após a aplicação (DAA) dos herbicidas.

Para isso, foi conduzido um experimento em campo, onde aplicaram-se os tratamentos com o herbicidas sobre a cultivar tolerante ("IRGA 422 CL”) e aos 194 DAA coletaram-se amostras intactas de solo, com auxílio de canos de PVC de $10 \mathrm{~cm}$ de diâmetro na camada de $0-10 \mathrm{~cm}$ de profundidade. Essas amostras de solo foram utilizadas para condução de um bioensaio em casa de vegetação, semeando-se azevém. Os tratamentos constaram de diferentes doses da mistura formulada de imazethapyr+imazapic contendo $75 \mathrm{~g}$ de imazethapyr e $25 \mathrm{~g}$ de imazapic por litro. Os tratamentos foram compostos das seguintes doses do herbicida formulado: 0,7L ha-1 em pré-emergência (PRE) seguido da aplicação de $0,7 \mathrm{~L} \mathrm{ha} \mathrm{h}^{-1}$ em pós-emergência (POS); 1,0L ha ${ }^{-1}$ em PRE; 1,0L ha ${ }^{-1}$ em POS; mais uma testemunha sem aplicação dos herbicidas. O bioensaio foi desenvolvido em casa de vegetação do Departamento de Fitotecnia da Universidade Federal de Santa Maria, no período de maio a julho de 2005, no delineamento experimental de blocos ao acaso, com cinco repetições, respeitando o delineamento utilizado a campo. O solo utilizado é classificado como Planossolo Hidromórfico eutrófico arênico, pertencente à Unidade de Mapeamento Vacacaí (EMBRAPA, 1999), com as seguintes características: $\mathrm{pH}_{\text {água }}(1: 1)=4,6$; $\mathrm{P}=3,7 \mathrm{mg} \mathrm{dm}^{-3} ; \mathrm{K}=0,14 \mathrm{cmolc} \mathrm{dm}^{-3}$ e M.O. $=10 \mathrm{~g} \mathrm{~kg}^{-1}$.

As sementes de azevém foram semeadas manualmente, sem incorporação, utilizando 10 sementes por unidade experimental. As amostras receberam semanalmente quantidade de água adequada à emergência e ao desenvolvimento inicial das plantas de azevém. A emergência das plantas ocorreu no dia $17 / 05 / 2005$. As variáveis analisadas foram: porcentagem de plantas estabelecidas aos três e aos 22 dias após a emergência (DAE), além de fitomassa seca aos 40 DAE. Após a última contagem de plantas estabelecidas (22 DAE), foi realizado desbaste, deixando três plantas por unidade experimental para a determinação de matéria seca aos 40 DAE. Os dados foram submetidos à análise de variância pelo teste de Tukey a 5\% de probabilidade de erro. Os dados de porcentagem de plantas estabelecidas foram transformados para análise pela transformação arcoseno.

Os resultados obtidos possibilitaram verificar que aos 194 DAA do produto não houve influência dos tratamentos na porcentagem de emergência do azevém, realizada aos três DAE (Tabela 1), entretanto, ocorreu menor emergência de azevém na testemunha, diferindo dos demais tratamentos. Esse resultado se deve provavelmente à desuniformidade de emergência das plântulas, que, por terem sido semeadas sem incorporação, apresentaram variações de contato semente-solo para absorção de umidade. Na segunda avaliação de emergência (22 DAE), bem como na avaliação da matéria seca, realizada aos 40 DAE, também não foram observadas diferenças significativas entre os tratamentos (Tabela 1 ).

Para o entendimento dos resultados obtidos, é fundamental a análise das condições ambientais do período. Durante a safra de arroz irrigado, o solo permaneceu, em média, 90 dias inundado, aumentando a mobilidade do herbicida e proporcionando condições para a ocorrência de fotodegradação das moléculas dos herbicidas presentes na lâmina de água, uma das principais formas de degradação das imidazolinonas em água (GOETZ, 1990; AVILA et al., 2006). Além disso, a sua percolação no perfil do solo é influenciada pela infiltração de água e controlada pelas características físico-químicas do solo (GOETZ, 1990; MANGELS, 1991). Por se tratar de solo de textura arenosa e de baixo conteúdo de matéria orgânica $\left(10 \mathrm{~g} \mathrm{~kg}^{-1}\right)$, essas condições favoreceriam a menor adsorção das moléculas dos herbicidas pelas partículas do solo, aumentando sua mobilidade (LOUX et al., 1989). Estudos indicam que herbicidas do grupo das imidazolinonas possuem pouca mobilidade horizontal (TU et al., 2004), porém verticalmente de 80 a $90 \%$ do herbicida aplicado pode se concentrar a partir dos $10 \mathrm{~cm}$ até os $20 \mathrm{~cm}$ do perfil do solo, podendo permanecer neste local por longos períodos (MANGELS, 1991; LOUX \& REESE, 1993), pois apresenta baixa taxa de degradação em condições anaeróbicas. Nas condições do bioensaio, que teve a semeadura do azevém realizada sem prévia incorporação das sementes, criou-se uma condição na qual as plantas se desenvolveram na superfície do solo, 
Tabela 1- Efeito residual da mistura formulada dos herbicidas imazethapyr+imazapic sobre azevém, cultivado em casa de vegetação, aos 194 dias após a aplicação dos herbicidas, em amostras de solo intactas coletadas em canos de PVC de $10 \mathrm{~cm}^{\text {de }}$ diâmetro $\left(0,008 \mathrm{~m}^{2}\right)$ e a 10cm de profundidade. UFSM/Santa Maria- RS, 2007.

\begin{tabular}{|c|c|c|c|}
\hline \multirow{2}{*}{ Tratamentos $^{6}$} & \multicolumn{2}{|c|}{ Plantas de azevém estabelecidas (\%) } & \multirow{2}{*}{$\begin{array}{c}\text { Matéria seca (g/pote) } \\
40 \mathrm{DAE}\end{array}$} \\
\hline & $3 \mathrm{DAE}^{1}$ & $22 \mathrm{DAE}$ & \\
\hline Testemunha & $30 b^{5}$ & $40^{\mathrm{ns}}$ & $0,27^{\mathrm{ns}}$ \\
\hline $\begin{array}{l}\text { 0,7L do produto formulado }\left(\mathrm{PF}^{2}\right) \mathrm{ha}^{-1} \text { em } \\
\mathrm{PRE}^{3}+0,7 \mathrm{~L} \text { do } \mathrm{PF} \mathrm{h}^{-1} \text { em } \mathrm{POS}^{4}\end{array}$ & $50 \mathrm{ab}$ & 50 & 0,19 \\
\hline 1L do PF ha ${ }^{-1}$ em PRE & $60 \mathrm{a}$ & 60 & 0,24 \\
\hline 1L do PF ha ${ }^{-1}$ em POS & $40 \mathrm{ab}$ & 50 & 0,22 \\
\hline CV (\%) & 15,5 & 16,5 & 20,3 \\
\hline Média & 45 & 50 & 0,23 \\
\hline
\end{tabular}

${ }^{1}$ Dias após a emergência do azevém.

${ }^{2}$ Dose referente à quantidade de produto comercial (Only ${ }^{\circledR}$ ). Cada litro de produto formulado continha $75 \mathrm{~g}$ de imazethapyr e $25 \mathrm{~g}$ de imazapic; ${ }^{3} \mathrm{PRE}=$ herbicida aplicado em pré-emergência do arroz e do arroz vermelho.

${ }^{4} \mathrm{POS}=$ herbicida aplicado em pós-emergência do arroz e do arroz vermelho.

${ }^{5}$ Médias seguidas de letras diferentes na coluna diferem entre si pelo teste de Tukey em nível de 5\% de probabilidade de erro.

${ }^{6}$ Tratamentos aplicados na safra de verão sobre arroz tolerante às imidazolinonas.

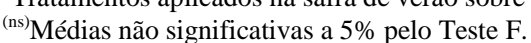

influenciando no volume de solo explorado pelas raízes, as quais, possivelmente, desenvolveram-se em camadas onde havia menor concentração dos herbicidas. Além disso, as amostras foram coletadas até a profundidade de $10 \mathrm{~cm}$, região na qual haveria menor concentração dos herbicidas.

Outro aspecto que deve ser ressaltado é a relação entre umidade do solo e disponibilidade do herbicida às plantas. A umidade do solo é um dos principais fatores que atuam na persistência dos herbicidas, pois altera a concentração e a mobilidade desses produtos no solo. Com o aumento da umidade, tem-se menor retenção da molécula do herbicida nas partículas do solo, deixando-o mais solúvel e disponível à absorção pelas raízes das plantas. O contrário ocorre em condições de solo com baixo conteúdo de umidade, condição esta apresentada no bioensaio, em que a adsorção do herbicida é maior pelas partículas do solo, ficando disponível em menor quantidade para absorção pelas plantas (ZHANG et al., 2001). Além disso, com a diminuição da umidade do solo, há um provável aumento na atividade microbiana devido à maior aeração do solo, o que contribui substancialmente na degradação das imidazolinonas, já que a ação microbiana é principal forma de degradação (GOETZ, 1990; WITT \& FLINT, 1997).

Apesar de não ter sido verificado fitotoxicidade às plantas de azevém semeadas no bioensaio aos 194 DAA, nesse mesmo experimento em campo foi verificado efeito sobre o arroz não-tolerante semeado um ano após a aplicação dos produtos, ou seja, após o bioensaio do azevém (SANTOS, 2006).
Essas diferenças nos resultados ocorreram provavelmente devido ao efeito residual do produto ser potencializado a partir da entrada da lâmina de água no arroz, pois, segundo WIK \& REINHARDT (2001), o herbicida lixiviado poderia voltar à zona de absorção das raízes por meio do movimento capilar realizado pela água, injuriando assim cultivares de arroz não-tolerante. Assim, em vista das características de solo, da mobilidade dos herbicidas e da característica de semeadura superficial do azevém, apesar de haver residual de herbicidas no solo, não houve efeito na emergência e na fitomassa seca do azevém aos 40 DAE, semeado em sucessão ao cultivo do arroz irrigado com aplicação de herbicidas do grupo das imidazolinonas.

\section{AGRADECIMENTOS}

Ao Conselho Nacional de Desenvolvimento Científico e Tecnológico (CNPq), pela concessão de bolsa de pesquisador para Enio Marchesan, Paulo Fabrício Sachet Massoni e Mara Grohs, e à Coordenação de Aperfeiçoamento Pessoal de Nível Superior (CAPES), pela concessão de bolsa ao aluno de Pós-graduação Fernando Machado dos Santos.

\section{REFERÊNCIAS}

AVILA, L.A. et al. Imazethapyr aqueous photolysis, reaction quantum yield, and hydroxyl radical rate constant. Journal of Agricultural and Food Chemistry, v.54, p.2635-2639, 2006.

COX, C. Imazapyr: herbicide factsheet. Journal of Pesticide Reform Imazapyr, v.16, n.3, p.16-20, 1996.

CROUGHAN, T.P. Application of tissue culture techniques to the development of herbicide resistant rice. Louisiana Agriculture, v.37, n.1, p.25-26, 1994.

Ciência Rural, v.38, n.6, set, 2008. 
EMBRAPA. Sistema brasileiro de classificação dos solos. Rio de Janeiro, 1999. p.412.

GRYMES, C.F. Response of soybean (Glycine max) and rice (Oryza sativa) in rotation to AC 263222. Weed Tecnology, v.9, p.504-511, 1995.

GOETZ, A.J. et al. Soil solution and mobility characterization of imazaquin. Weed Science, v.34, p.788-793, 1986.

GOETZ, A.J. Degradation and field persistence of imazethapyr. Weed Science, v.38, p.421-428, 1990.

LOUX, M.M. et al. Availability and persistence of imazaquin, imazethapyr and clomazone in soil. Weed Science, v.37, p.259-267, 1989.

LOUX, M.M.; REESE, K.D. Effect of soil pH on adsorption and persistence of imazaquin. Weed Science, v.40, n.3, p.490496, 1993.

MANGELS, G. Behavior of the imidazolinone herbicides in soil: a review of the literature. In: SHANER, D.L.; O'CONNOR,
S.L. The imidazolinone herbicides. Boca Raton: CRC, 1991. p.191-209.

SANTOS F.M. Alternativas de controle químico do arroz vermelho e persistência dos herbicidas (imazethapyr + imazapic) e clomazone na água e no solo. 2006. $72 \mathrm{f}$. Dissertação (Mestrado em Agronomia) - Curso de Pós-graduação em Agronomia, Universidade Federal de Santa Maria.

TU et al. Imazapic. Weed control methods handbook. London: Academic, 2004. Cap.7, p.1-7.

WIK, L.J.V.; RINNHARDT, C.F. A biossay technique detects imazathapyr leaching and liming-dependent activity. Weed Technology, v.15, p.1-6, 2001.

WITT, W.W.; FLINT, J.F. Microbial degradation of imazaquin and imazethapyr. Weed Science, v.45, p.586-591, 1997

ZHANG, W. et al. Effect of moisture on efficacy of imazethapyr in greenhouse. Weed Technology, v.15, p.355-359, 2001. 